\title{
MUSEO DE LA ROMANIZACIÓN EN CALAHORRA (LA RIOJA): ACTIVIDADES DIDÁCTICAS 2012
}

\author{
Rosa Aurora Luezas Pascual \\ Museo de la Romanización de Calahorra
}

\begin{abstract}
RESUMEN: Se presentan las actividades relacionadas con la didáctica de las Ciencias Sociales diseñadas por el Departamento de Educación y Acción Cultural del Museo de la Romanización en Calahorra con el fin de acercar sus contenidos de forma clara y comprensiva. Estas se han articulado en torno a las visitas de los centros escolares y a cuatro tipos de talleres, relativos a los cursos del primer ciclo de Educación Primaria para niños. Para todos ellos se ha producido un material didáctico específico y adaptado a cada una de las actividades.
\end{abstract}

PALABRAS CLAVE: Programa difusión fondos, Museo de la Romanización Calahorra, talleres: legionario, mosaico, vestido, juegos romanos.

\section{MUSEUM OF THE ROMANIZATION OF CALAHORRA (LA RIOJA): EDUCATIONAL ACTIVITIES 2012}

\begin{abstract}
We presents the activities related to the teaching of Social Sciences designed by the Educational Department of the Museum of the Romanization of Calahorra in order to bring in a clear and comprehensive content. These have been organized around visits to schools and four types of workshops, courses on the first cycle of primary education for children. For them there has been a teaching material and adapted to each of the activities.

KEYWORDS: Dissemination program funds, the Museum of Romanization Calahorra, workshops: Legionnaire, mosaic, clothing, Roman games.
\end{abstract}

Recibido: 10/01/2013

Aceptado: 22/04/2013

\section{INTRODUCCIÓN}

El Museo de la Romanización en Calahorra se inaugura el 16 de junio de 2009, con el fin de rememorar la importancia de una ciudad bimilenaria como Calagurris 
Ivlia Nassica dentro de la Hispania romana, que obtuvo el rango de municipium civium romanorum. Dicho centro museístico está dedicado a la exposición, conservación, investigación y difusión de la huella del mundo romano en La Rioja y se une a la red de espacios expositivos que está distribuida por la comunidad autónoma.

A través de sus tres plantas y sus cinco salas expositivas se hace un recorrido desde los pobladores anteriores a la llegada de los romanos hasta el siglo IV-V d. C. Los contenidos del centro presentan un enorme potencial desde el punto de vista pedagógico y didáctico como veremos a continuación.

Las colecciones son aportadas tanto por el Museo Municipal de Calahorra como por el Museo de la Rioja. El discurso, con cinco áreas temáticas principales, lo integran más de un millar de piezas arqueológicas procedentes no solo de Calahorra, sino de todo el territorio actual de la Rioja: Graccurris (Alfaro), Vareia (Varea), Tritium Magallum (Tricio), Libia (Herramélluri), etc.

La Sala I esta dedicada a los precedentes de la romanización, es decir, a la cultura celtibérica en la Rioja y en ella se pueden apreciar testimonios de la cultura material de la población indígena: cerámicas elaboradas a torno y decoradas con motivos pintados, un molino giratorio, objetos de adorno personal, una estela funeraria. La museografía de esta sala se completa con maquetas sobre la vivienda celtibérica o el horno para la cocción cerámica, además de ilustraciones como el mapa de Hispania según Estrabón, interactivos o pantallas táctiles que permiten ampliar la información sobre la cultura celtibérica en le Rioja.

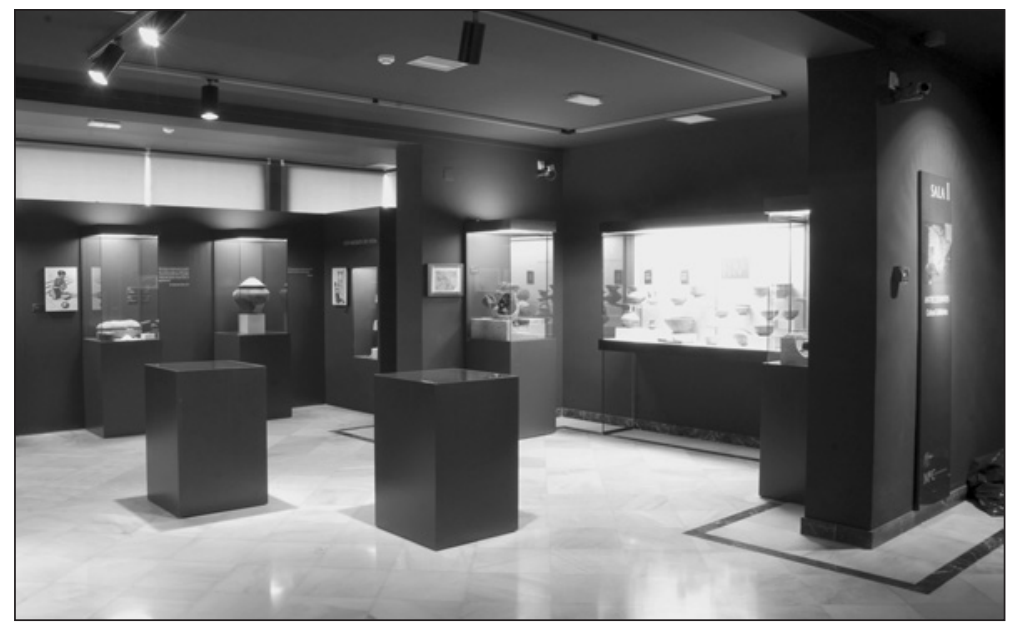

Figura 1. Sala I. Los precedentes: la cultura celtibérica en la Rioja

La Sala II, que Ileva por título la guerra y la conquista. El comienzo de la romanización, va pintada en color rojo sangre, simbolizando la guerra. Un audiovisual de varios minutos de duración introduce al espectador en el mundo de las legiones romanas y las guerras de conquista. También otra pantalla táctil permite al visitante conocer de forma pormenorizada la conquista y las distintas unidades militares cons- 
tatadas en el territorio riojano, entre las innovaciones romanas: la escritura, la red de calzadas, la moneda, etc.

A través de las piezas expuestas, tanto en las vitrinas, como de forma exenta sobre peanas se pueden ver:

- Algunas de las armas de los soldados romanos: espadas, un umbo de escudo, lanzas, proyectiles de honda de la propia Calahorra y proyectiles de ballista (catapulta) procedentes de un solar de la calle Tilos, que indican el asedio sufrido por la ciudad indígena de kalakorikós durante las guerras de conquista.

- Dos lapidas funerarias de soldados romanos que murieron en Varea.

- Los primeros indicios de la romanización están representados por mosaicos de opus signinum de Contrebia Leukade (Aguilar del Río Alhama) y Calagurris (Calahorra) o cerámicas procedentes directamente de Italia (campanienses, engobe interno rojo-pompeyano, platos de borde bífido), así como un miliario procedente de la calle Arrabal de Calahorra que ilustra las calzadas romanas. Debido a la importancia estratégica de Calagurris, la ciudad contó con ceca propia de acuñación de moneda, tanto indígena como latina.

El equipamiento museográfico de esta sala se completa con los mapas de la conquista de Hispania y del valle del Ebro, otro mapa de las comunicaciones en el Imperio: la red viaria de Hispania y del actual territorio de la Rioja. Por lo que respecta al sistema monetario del Alto Imperio, varios paneles ilustran sobre la dispersión de las monedas de Calagurris y los magistrados montéales calagurrutanos.

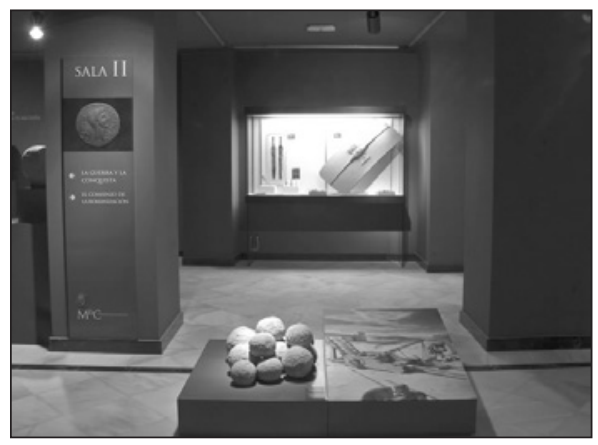

Figura 2. Sala II. La guerra y la conquista

La Sala III está dedicada al ámbito doméstico, bajo el título la domus. En ella se puede ver cómo era una casa romana por dentro y por fuera, es decir, los materiales empleados en la construcción de una vivienda, que se han ordenado desde el sótano hasta el tejado (elementos de la calefacción romana, tuberías para la conducción de agua en cerámica o en plomo, placas de mármol, ladrillos para las paredes, tejas planas y curvas de la techumbre, etc. Se exponen las técnicas constructivas y los revestimientos decorativos con mosaicos y pinturas murales. 
Los elementos de decoración de la casa están representados por pavimentos musivarios de la ciudad de Calahorra: mosaicos de las calles Enramada, San Sebastián, Cabezo; pinturas murales del complejo termal de La Clínica; fragmentos de esculturas, elementos de decoración de muebles en bronce, bisagras de mobiliario en hueso, etc.

A continuación pasamos a ver las vasijas de cerámica utilizadas por los romanos en la preparación de alimentos, dentro de la cocina, así como para la cocción de los mismos representados por ollas, cuencos trípodes, etc. Seguidamente podemos ver las vajillas utilizadas en la mesa, elaboradas en los talleres de Tritium Magallum (Tricio) o vasos de paredes finas para beber.

El ámbito doméstico se completa con la iluminación (lucernas romanas) y la escritura (tinteros de cerámica y vidrio) y varios stylus o punzones para escribir sobre tablillas de cera.

Bajo el título del Espejo de Venus, podrás ver los elementos de tocador y el adorno personal, representados por unas pinzas de depilar procedentes de Varea, agujas para el pelo, broches de cinturón, cuentas de collar, etc.

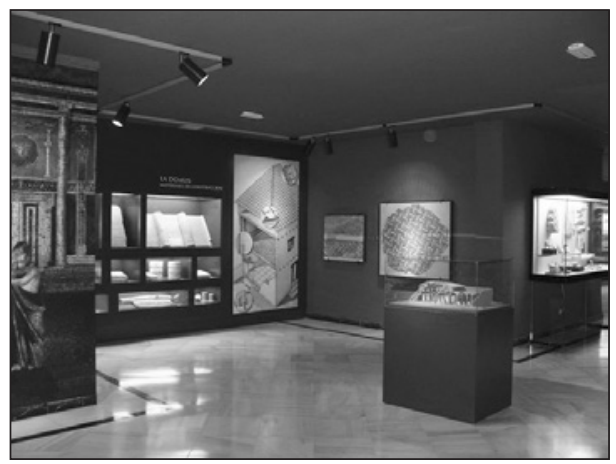

Figura 3. Sala III. Domus: la casa romana

La Sala IV está dedicada a los negocios o actividades económicas. En este caso es el color naranja el que la identifica, en alusión al fuego necesario para cocer el barro, soplar el vidrio o fundir el hierro, bronce, plomo, etc.

La agricultura se basaba en los tres cultivos mediterráneos: el trigo, la vid y el olivo. Así la sala expone los elementos empleados en la molienda del trigo: un molino de piedra de tracción animal, prensas de vino o aceite y envases como ánforas —recipiente para el almacenaje y transporte de vino - o tinajas.

Las actividades artesanales están representadas por la industria alfarera de Tritium Magallum (Tricio) con los moldes empleados para decorar las vajillas de lujo, carretes o ajustadores para la colocación de las vasijas en el horno, piezas defectuosas, deformadas o quemadas, moldes para la elaboración de candiles o figurillas de Venus. Estos talleres abastecieron en época imperial a todos los puntos del Imperio.

Otras artesanías como la del vidrio están ilustradas por escorias de pasta vítrea del taller de La Maja (Pradejón-Calahorra), la del bronce por restos del taller de broncista de Varea o la del hueso por el taller de industria ósea de Calahorra. 
A continuación se recoge el sistema de pesas y medidas empleado en las actividades comerciales, representado por balanzas y pesas de plomo, piedra, o bronce. El comercio exterior muestra vasijas de importación: terra sigillata gálica, vasijas africanas de cocina, etc.

La Sala V centra su temática en el ocio, la religión, el culto y el juego. Al principio de la misma se pueden ver una serie de inscripciones honoríficas halladas en Calahorra: epígrafes monumentales procedentes de la edilicia pública. El ocio está además representado por las carreras del circo de Calagurris, que estaba situado en el actual Paseo del Mercadal. En la vitrina dedicada al juego se pueden contemplar el vaso de las carreras circenses procedente de La Maja; varias tabas y una reproducción de un tablero de juego con sus fichas. La religión está plasmada a través de las esculturas romanas (Júpiter, Cupido, dama de Calahorra, "Afrodita"), o el mundo funerario a través de varias estelas o lápidas funerarias.

En esta última planta un documental de once minutos de duración hace un recorrido de la romanización en la Rioja, desde la fundación de Graccurris en el 179 a.C., las guerras hasta la introducción del cristianismo. Presta especial atención al papel protagonista jugado por Calahorra durante las guerras sertorianas y la destrucción de Kalakorikós. Todo ello ha sido posible en base a recreaciones obtenidas de películas de ficción, imágenes del Mercaforum (mercado romano) de Calahorra, de la officina monetalis de la Asociación de Amigos de la Historia de Calahorra y de restos arqueológicos romanos que todavía se conservan.

La museografía del centro utiliza tanto herramientas museográficas tradicionales (vitrinas con material arqueológico original, paneles didácticos, mapas...) como las nuevas tecnologías de la comunicación incorporadas al montaje museográfico interactivos, audiovisuales y video-guías que proporciona información en tres idiomas: español, francés e inglés.

\section{DesCriPCión DE LAS ACtIVIDADES EDUCATIVAS}

A lo largo del año 2012 el Museo de la Romanización, con el fin de llevar a cabo la dinamización del mismo, ha desarrollado todas las mañanas de los martes y jueves, entre los meses de febrero y junio los talleres "Ven a conocer Roma". Este plan de acción educativa ha sido diseñado específicamente para alumnos de Educación Primaria.

Los grupos de visitantes más relevantes con los que cuenta el centro son estudiantes de Educación Secundaria (ESO), estudiantes universitarios, especialistas e investigadores y jubilados. Por este motivo, se ha organizado la actividad, con el fin de atraer al público infantil, ávido de conocimientos.

Marco legal: La Ley Orgánica de Educación 2/2006 de 3 de mayo, el Real Decreto $151 / 2006$ por el que se establecen las enseñanzas mínimas de Educación Primaria y el Decreto 4/2011 de 28 de enero por el que se establece el currículo de dicha etapa para la Comunidad Autónoma de la Rioja.

Público receptor: La iniciativa va dirigida a niños de entre siete y doce años, es decir, alumnos de primero, segundo y tercer ciclo de Primaria. La misma propuesta se ha adaptado adecuadamente a los conocimientos de cada grupo de edad. 
Áreas de conocimiento implicadas: con esta actividad los escolares podrán conocer con todo tipo de detalles las características sociales y culturales de la Antigua Roma. Un viaje al pasado, a la época de esplendor de una ciudad bimilenaria como Calagurris Ivlia Nassica. Afecta fundamentalmente al área de Ciencias Sociales, aunque también se tratan otros aspectos del currículo educativo como el área de Educación Física (taller de los juegos romanos) y habilidades manuales (talleres del mosaico, vestido y legionario romanos).

Lugar en el que se desarrolla: las propias salas del Museo de la Romanización de Calahorra.

Duración de la actividad: se ha desarrollado durante el segundo y tercer trimestre del curso. Cada uno de los talleres tiene una duración mínima de 45 minutos y máxima de 60 minutos.

\section{Objetivos}

La interrelación escuela-museo es cada vez mayor de cara a completar la formación en Ciencias Sociales, por ello uno de los objetivos planteados con esta iniciativa es hacer accesibles los contenidos del museo al público escolar, es decir acercarlos de forma clara y comprensiva.

Para ello, los departamentos de Educación y Difusión de los museos cuentan con muy diversos recursos en connivencia con las necesidades de los planes de estudios de cada nivel educativo. El Museo de la Romanización de Calahorra, desde que inició su andadura el año 2009, completa su oferta de visitas guiadas y talleres educativos con la edición de material didáctico en formato de cuadernillo, permitiendo al alumnado un uso de la arqueología de época romana como fuente histórica, a la vez que difunde los contenidos de ésta más allá de sus aspectos histórico-artísticos. Para las visitas autoguiadas el centro cuenta con diversos recursos como audiovisuales, pantallas táctiles o video-guías, además de la página web del Ayuntamiento de Calahorra, donde puede encontrar una amplia información, además de contenidos en formato pdf.

Los talleres son uno de los instrumentos de actividades del museo que Ángela García Blanco y Teresa Sanz Marquina (1979: 47) denominan de acción directa o dina-museum. Estos talleres buscan la participación del visitante motivándole para llevar a la práctica los conocimientos adquiridos, la motivación de los alumnos.

Los participantes en el taller tendrán la oportunidad de realizar una aproximación a la sociedad de la antigua Roma conociendo las técnicas decorativas de los suelos romanos, el traje de un legionario romano y sus armas, las prendas del vestido tanto masculino como femenino y sus adornos y los edificios de espectáculos tanto el circo romano: edificio, partes de la construcción, bigas y cuadrigas, como el anfiteatro y sus gladiadores.

Los talleres van dirigidos a alumnos de primaria (primero, segundo y tercer ciclo) de los centros educativos con edades comprendidas entre 7 y 12 años, de $1^{\circ}$ a $6^{\circ}$ que podrán conocer con todo tipo de detalles las características sociales y culturales de la antigua Roma. 


\section{DesarRollo De LAS ACTIVIDADES}

\section{Metodología}

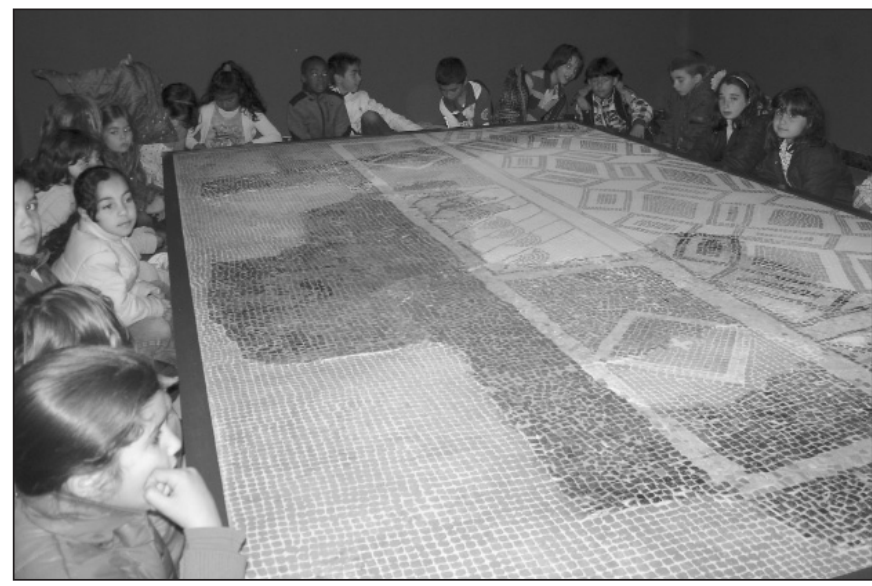

Figura 4. Visita del grupo escolar a la sala de exposiciones

- Fase I: Visita del grupo escolar a la sala de exposición relacionada con la temática del taller, para establecer un contacto directo entre las piezas y el contexto histórico de la sala así como el espacio que las rodea (Figura 4).

- Fase II: El monitor del taller realizará una explicación verbal previa en un lenguaje sencillo y adaptado a la edad de cada uno de los grupos escolares participantes. Dicha explicación no tendrá una duración superior a los veinte minutos.

- Fase III: Realización del taller de manera lúdica y creativa, se trata de que aprendan a la vez que se divierten, fomentando el interés de los alumnos por la cultura y civilización romana. En esta fase se realizarán las fichas didácticas específicas para cada grupo de edad, que se llevarán a cabo bajo la supervisión de los profesores.

\section{Difusión}

La gestión ha sido realizada desde el propio museo, enviando la oferta a los centros de enseñanza de la propia Calahorra y poblaciones limítrofes. También se ha elaborado un díptico con el contenido de cada uno de los talleres y el material necesario que cada niño debe aportar para la realización del mismo. La actividad "Ven a conocer Roma" es gratuita previa inscripción en el Departamento de Educación y Acción Cultural del Museo. La solicitud debe realizarse vía telefónica o vía e-mail. Las visitas tienen lugar los martes y jueves, previa elección de hora por parte del profesorado. 


\section{Materiales didácticos complementarios}

Como señalan Joan Santacana y Nuria Serrat (2007: 125) son una de

las herramientas didácticas que se pueden emplear para hacer más accesible la exposición. Tienen como fin ampliar la información que ofrece la exposición y que ayudan a una mayor comprensión del mensaje expositivo.

El educador debe presentar información complementaria a la idea central de la exposición, tendente a profundizar el mensaje expositivo.

Para las fases I y II descritas anteriormente, el Museo de la Romanización de Calahorra ha elaborado una serie de materiales complementarios, cuyo fin es ayudar a los niños a visualizar la explicación previa a la realización de cada uno de los talleres.

Además para cada una de las salas de romanización se ha diseñado un taller. Hemos obviado la Sala I dedicada a los precedentes, centrándonos en las cuatro restantes. Así para la Sala II dedicada a la guerra y la conquista se ha ideado el taller del Legionario Romano.

\section{Taller Conoce el traje del legionario romano y sus armas}

Plotter del legionario romano

Consta de las siguientes imágenes:

1. Recortable de un legionario romano con su uniforme y sus armas para vestir. Cada niño recortará los siguientes elementos:

- Galea o casco

- lorica segmentata o coraza

- túnica de lana

- scutum o escudo rectangular

- pilum o jabalina

- cingulum o cinturón

- caliga o sandalia

2. Fotografía de detalle una caliga o sandalia romana en la que se aprecian los clavos de hierro que formaban parte de la suela.

3. Dibujo a blanco y negro de un soldado a caballo o equites.

4. Lámina con la formación de una legión romana: manípulos, cohortes y centurias. Dirigido a niños de etapas superiores, dada la complicación y grado de dificultad del vocabulario.

5. Una ballista o máquina de artillería de época romana.

6. Fotografía de un legionario romano con su equipo completo.

7. Dibujo de un campamento romano (castra).

De forma previa los niños han podido contemplar durante unos minutos el audiovisual de esta sala con escenas de guerra de la película Gladiator. 


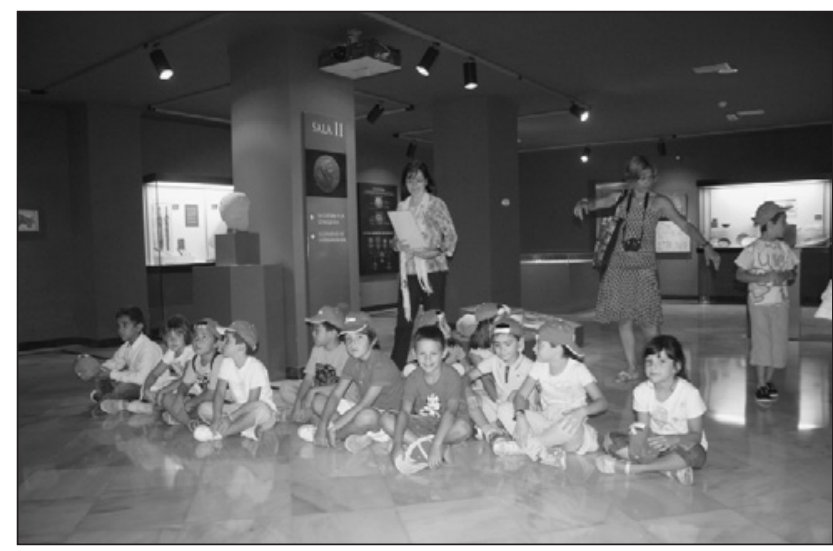

Figura 5. Realización del taller del Legionario romano

Esta actividad se lleva a cabo delante de la vitrina dedicada al armamento romano ubicada en la Sala II La guerra y la conquista, donde los niños pueden ver una serie de armas de la infantería romana: espadas de la Azucarera de Alfaro, un puñal, una punta de lanza, umbo de escudo, punta de flecha de Calahorra, glandes o proyectiles de honda. Una de las esculturas expuestas en esta sala, una cabeza de guerrero procedente de la calle Grande de Calahorra es un buen ejemplo para que los niños vean un casco romano esculpido. En lo que respecta al calzado, en la vitrina de la Sala III dedicada al tocador el público infantil puede contemplar una recreación de una caliga: suela de calzado con los clavos de hierro originales, procedentes de la villa romana de Los Ladrillos en Tirgo.

En lo que atañe a la caballería contamos con elementos del equipamiento procedentes de Varea y una serie de botones de arreos de caballo.

En lo que concierne a la artillería y máquinas de asedio de guerra, disponemos de una serie de proyectiles de ballista, que nos ilustran sobre las guerras sertorianas y el asedio sufrido por la antigua ciudad indígena de Kalakoríkós en el siglo I a.C.

Mediante una ficha recortable los niños aprenderán las diferentes partes del equipo de un legionario romano (casco, coraza, sandalias...) así como las armas utilizadas en base a los hallazgos en un campamento romano: espada, puñal, escudo, jabalina, etc. También buscarán en la vitrina de la Sala II La guerra y la conquista las diferentes armas de la ficha. Y posteriormente pintarán en diferentes colores las distintas partes del uniforme del soldado de infantería (Figura 5). La realización de las fichas didácticas cuenta con la supervisión de sus respectivos profesores.

\section{Taller Construye un mosaico romano}

Para la Sala III la domus o casa romana, se ha elegido la reproducción de un mosaico romano encontrado en el casco antiguo calagurritano, en concreto el mosaico de la calle Cabezo.

La actividad se lleva a cabo primero en la Sala II donde hay varios mosaicos de opus signimun del siglo I a.C., procedentes de Contrebia Leukade y de la calle 
Pastores de Calahorra, y posteriormente en la Sala III donde se ubican los mosaicos de opus tessellatum de las calles Enramada, Cabezo, San Sebastián, etc. Los niños tienen la oportunidad de contemplar y ver las divergencias entre ellos. Así se les motiva para que los analicen, observen y aprecien las similitudes y diferencias entre ellos, en base a una serie de preguntas como: colores de las teselas empleadas, en cual de ellos hay más teselas, motivos decorativos, etc. La finalidad es establecer un diálogo con los escolares para propiciar la observación y el análisis de las piezas expuestas.

\section{Plotter del mosaico romano}

Desde el departamento de educación y comunicación del Museo de la Romanización se ha elaborado un plotter como material didáctico complementario con las siguientes ilustraciones:

- Fotografía de una mosaico romano.

- Teselas o cubos de pizarra que componen los mosaicos romanos.

- Los diferentes tipos de mosaicos del mundo romano: opus signinum, opus sectile, opus tessellatum y opus vermiculatum.

- Las diferentes capas que componen un mosaico romano: statumen, nucleus, rudus, teselas.

- Herramientas necesarias para tallar las teselas: martillo, tenazas, cincel, etc.

- Dónde se colocaban los mosaicos romanos: edificios públicos (termas) o privados (domus -casas en la ciudad- o villae --casas de campo-).

- Temas representados en los mosaicos romanos: escenas de la vida cotidiana (agricultura pesca, cacerías...), espectáculos (luchas gladiatorias, carreras del circo, luchas de fieras...), mitología (dioses, animales fantásticos).

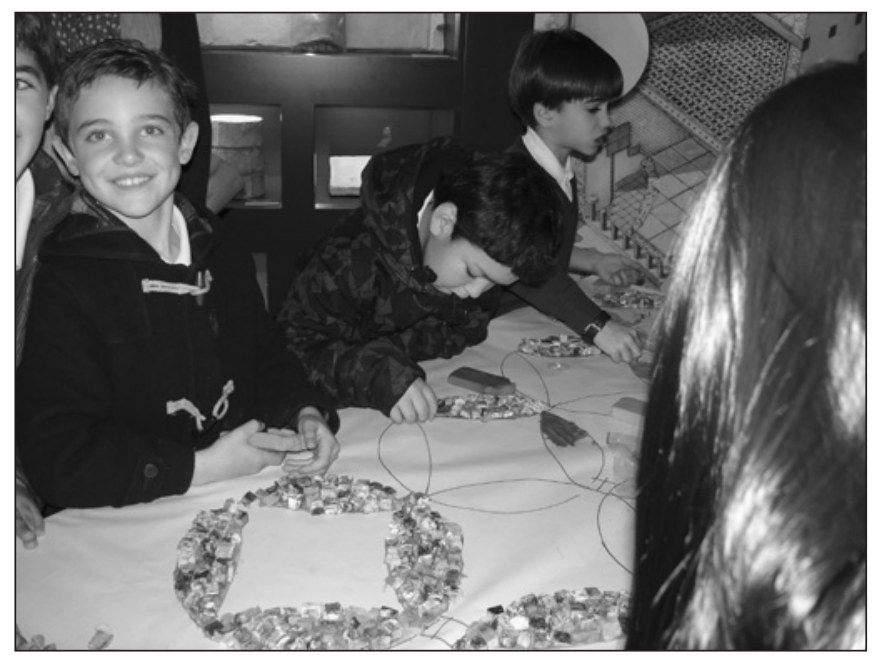

Figura 6. Realización del taller del mosaico romano 
Mediante teselas originales de época romana y sobre una base de plastilina los niños reproducirán una parte de uno de los mosaicos expuestos en el Museo, y procedente del casco antiguo calagurritano (Figura 6). La finalidad es que conozcan el proceso de elaboración de un mosaico romano, la terminología y aprendan a distinguir entre un mosaico de opus signinum del siglo I a.C. y uno de opus tessellatum. La actividad se completa en el caso de los ciclos educativos superiores con un puzzle de otro de los mosaicos romanos calagurritanos.

\section{Taller El vestido (masculino, femenino) y el adorno romanos}

Con la ayuda de los murales del triclinium de la Sala III La domus y de la Sala IV el mercado, los niños aprenderán a diferenciar los vestidos de época romano tanto el masculino: la toga, como el femenino: la palla, la túnica, así como los diferentes adornos y complementos: fíbulas, pendientes, anillos, acus para el pelo, etc. El calzado es otra parte importante de la indumentaria, aprenderán términos como perones, calcei o caliga.

La apariencia de la mujer era muy importante en el mundo romano, por lo que se utilizaban frecuentemente cremas o perfumes, plasmados a través de ungüentarios o vasos de vidrio, un fragmento de espejo de bronce procedente de Vareia (Varea, Logroño), unas pinzas para depilar de este mismo yacimiento, un medallón de bronce o entalles, cuentas de collar, anillos, etc. Todos estos elementos se pueden contemplar en la Sala III, concretamente en la vitrina que bajo el título el Espejo de Venus se dedica al tocador.

Plotter del vestido y adorno romanos

En este caso el plotter que el Museo de la Romanización ha elaborado como material complementario consta de las siguientes ilustraciones:

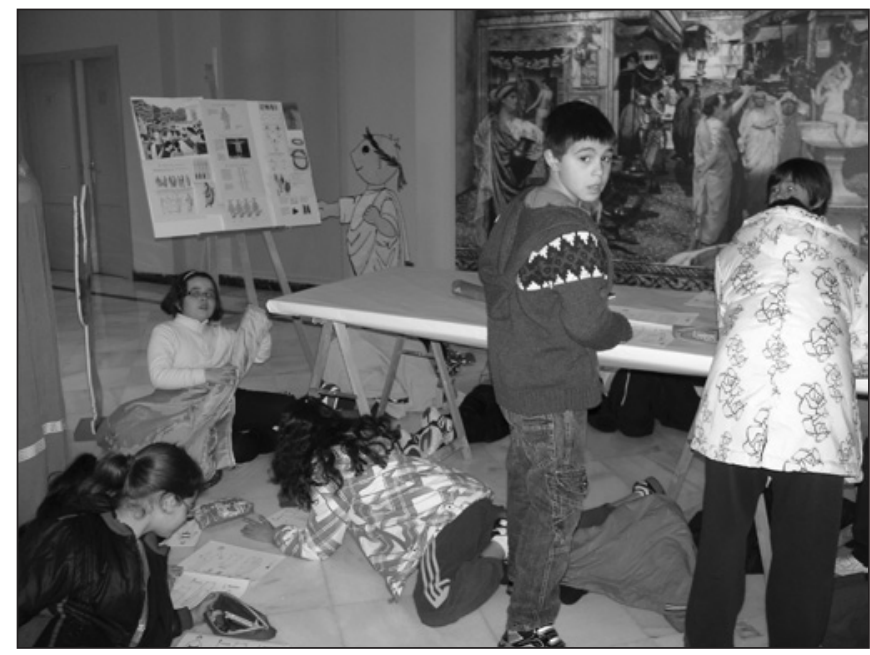

Figura 7. Realización del taller del vestido y los complementos 
Vestido romano

- Imagen de una túnica romana: patrón de la misma, forma.

- Imagen de una toga romana: patrón y forma.

- Vestido de los senadores romanos o toga praetexta con una banda ancha de púrpura en el borde o las características franjas de color púrpura en la túnica.

- Imagen de la indumentaria femenina: túnica, stola, palla.

- Imagen de los diferentes tipos de calzado romanos: zapatos de piel-perones, zapatos de los senadores-calcei, una caliga o sandalia del legionario con los característicos clavi caligae (tachuelas de hierro).

\section{El adorno romano}

- Fotografía del pendiente aparecido en la cloaca romana de Calahorra, fotografía de una fíbula o hebilla romana, los aci o agujas para el cabello de hueso.

- El peinado es otro elemento importante de la indumentaria: algunos de ellos eran complicados. En este caso se presta especial atención al peinado de una de las esculturas expuestas en la Sala V: la dama de Calahorra.

- En el caso de la indumentaria femenina, los niños tienen la oportunidad de contemplar otra de las esculturas expuestas en la Sala V: la conocida como Afrodita, que en realidad es una escultura que representa a Melpómene Farnese, musa de la tragedia.

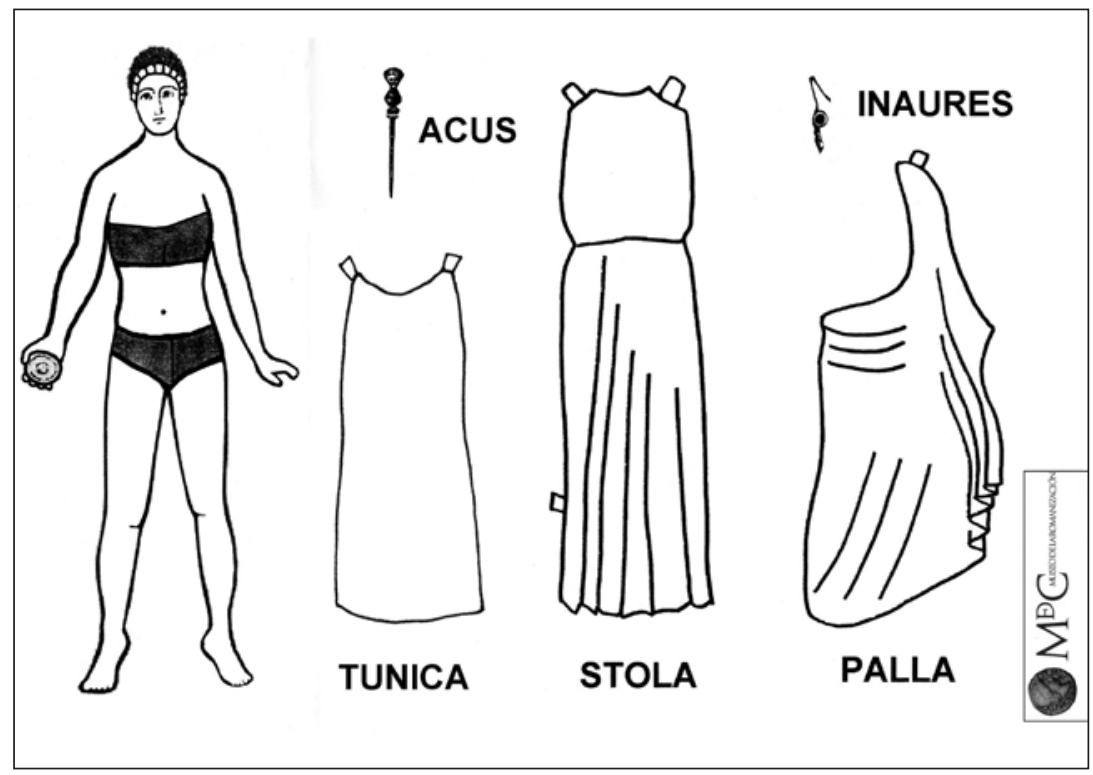

Figura 8. Recortable vestido femenino 


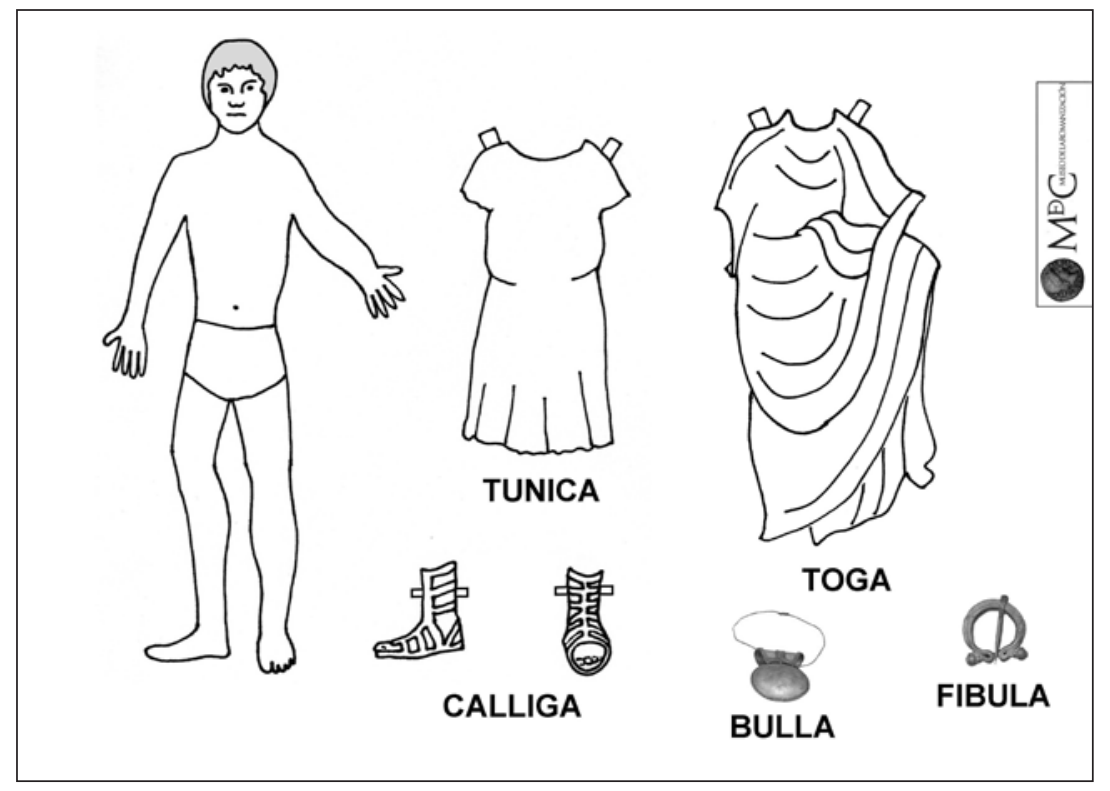

Figura 9. Recortable vestido masculino

Delante de la vitrina que lleva por título el Espejo de Venus, los niños identificarán cada uno de los elementos de tocador y el adorno personal. A continuación cada uno de ellos recibe un recortable doble muñeco/-a romano/a con las diferentes prendas de su indumentaria: tunica, toga, caliga en el caso masculino y túnica, stola, palla, acus, inaures en el caso femenino, para colorear y recortar. Esta ficha, que ha sido diseñada desde el propio centro museológico, se adapta perfectamente a los tres ciclos educativos.

\section{Taller Edificios de espectáculos: el circo y el anfiteatro romanos}

La actividad se lleva a cabo en la Sala V Otium, y en concreto delante del mural dedicado al circo romano de Calagurris, donde los niños aprenderán a diferenciar un circo de un anfiteatro, sus distintas formas arquitectónicas y a qué clase de juegos o espectáculos se destinaba cada uno de ellos: carreras de cuadrigas, luchas gladiatorias, venationes o luchas entre animales, etc. Aprenderán los nombres de los distintos gladiadores y su equipo: retiarius, samnita y secutor.

Plotter de los Juegos: circo y anfiteatro

Juegos circenses

- Fotografía del Circo Máximo de Roma.

- Fotografía de una cuadriga o carro tirado por cuatro caballos.

- Vaso de las carreras de carros del ceramista Gaio Valerio Verdulo procedente del alfar romano de la Maja (Calahorra), fechado en el siglo I d.C. 
- Dibujo en blanco y negro de un circo romano con los nombres de sus diferentes partes: arena, spina, carceres, podium, metas, porta triumphalis, porta pompae.

- Dibujo con la reconstrucción hipotética del circo romano de Calagurris y su ubicación dentro de la ciudad de Calahorra, así como los restos actuales que se conservan en el entorno del Parador Nacional de Turismo, en el Parque de la Era Alta.

Juegos gladiatorios

- Fotografía del Coliseo de Roma y de unos gladiadores.

- Dibujo en blanco y negro con las diferentes partes de un anfiteatro romano.

- Dibujos para colorear de diferentes tipos de gladiadores romanos: secutor, retiarius, samnita...

- Recortable de un gladiador romano y su equipo para vestir.

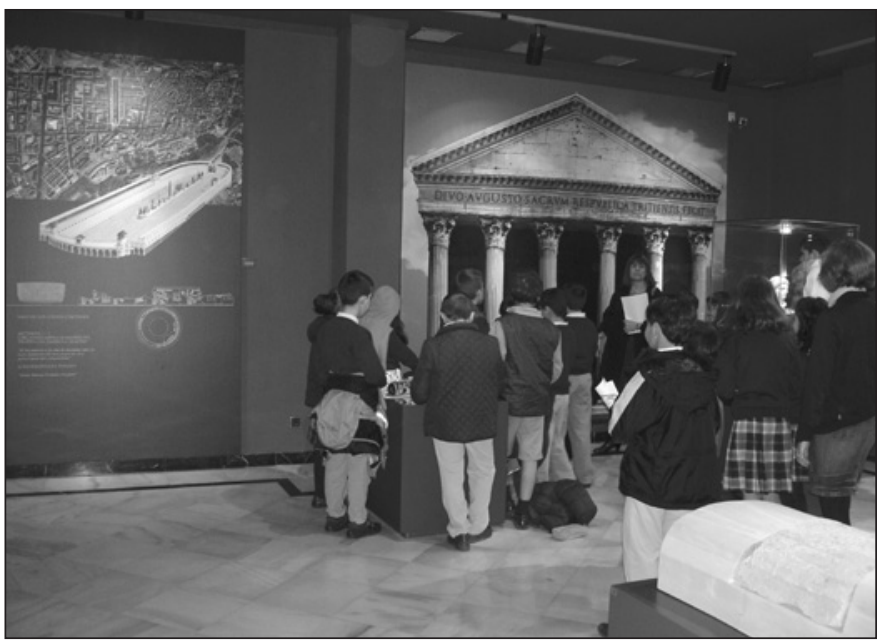

Figura 10. Realización del taller de los juegos

El taller centra su atención en el mural con la fotografía aérea de Calahorra en la actualidad y la silueta de ubicación del trazado del circo romano en el actual Paseo del Mercadal (Figura 10). Otro elemento importante de esta actividad educativa es la vitrina dedicada a los juegos. Por lo que respecta a los juegos públicos, el vaso de paredes finas decorado con una carrera de cuadrigas procedente del centro alfarero de la Maja, es la pieza estrella de esta actividad. Los niños después de una explicación previa que centra su atención en los ludi circenses del municipium Calagurris Ivlia Nassica, observan el vaso de las carreras del circo con la representación de una escena del circo y las leyendas alusivas a la misma. 
En lo que atañe a los juegos privados, se ilustran el juego de las tabas y el juego del tres en raya a través de una reproducción de un tablero de juego y una variada gama de fichas de juego o calculi realizadas en distintos materiales: mármol, hueso, cerámica, piedra, etc.

El objetivo de este taller es que el público infantil sea consciente de la existencia de un circo en la antigua Calagurris Ivlia Nassica, de su emplazamiento y de los restos que se conservan en la actualidad en el Paseo del Mercadal y en los jardines del Parque de la Era Alta (un tramos de la pared sur y varias canalizaciones). Incluso se sugiere al público escolar la posibilidad de realicen una visita a los mismos acompañados de sus padres.

Finalmente los niños realizarán una ficha didáctica bajo la supervisión del monitor del taller y de sus correspondientes profesores. Se han diseñado dos fichas adaptadas a los distintos niveles educativos. La ficha dedicada al circo romano va dirigida a los ciclos superiores, y reproduce un dibujo del edificio, su alzado y diferentes partes. Los niños deberán rellenar los nombres de las mismas. La otra ficha, destinada a los ciclos inferiores, está dedicada a los juegos gladiatorios: mediante un recortable para colorear, los niños vestirán a un gladiador romano.

La actividad 'Ven a conocer Roma', en unos casos, se completa con un recorrido guiado por las salas expositivas dedicadas al mundo hispano-romano, que exhiben un amplio catálogo de piezas, y en otros con la presentación audiovisual de la romanización de la Rioja instalado en la segunda planta del edificio.

\section{VALORACIÓN DE LA EXPERIENCIA}

MUSEO DE ROMANIZACIÓN CALAHORRA. Campaña Enero/Junio 2012

\begin{tabular}{|c|c|c|c|c|}
\hline TALLER & $\begin{array}{c}\mathrm{N}^{\circ} \\
\text { de grupos }\end{array}$ & $\begin{array}{c}\mathrm{N}^{\circ} \\
\text { de alumnos }\end{array}$ & Procedencia & Cursos \\
\hline Mosaico & 13 & 350 & $\begin{array}{l}\text { Calahorra: } \\
\text { Quintiliano, San } \\
\text { Andrés, Teresianas, } \\
\text { Angel Oliván } \\
\text { CRA de Ausejo } \\
\text { Centro Ancora }\end{array}$ & $\begin{array}{l}1^{\circ}, 2^{\circ}, 3^{\circ}, 4^{\circ}, 5^{\circ} \\
\text { Primaria }\end{array}$ \\
\hline Legionario & 3 & 76 & $\begin{array}{l}\text { Calahorra: } \\
\text { Quintiliano, San } \\
\text { Andrés, Angel Oliván } \\
\text { Centro Ancora }\end{array}$ & $2^{\circ}, 4^{\circ}$ Primaria \\
\hline Juegos & 7 & 175 & $\begin{array}{l}\text { Calahorra: } \\
\text { Quintiliano, San } \\
\text { Andrés, Teresianas }\end{array}$ & $1^{\circ}, 4^{\circ}, 6^{\circ}$ Primaria \\
\hline Vestido & 5 & 125 & $\begin{array}{l}\text { Calahorra: } \\
\text { Quintiliano, San } \\
\text { Andrés }\end{array}$ & $3^{\circ}$ y $4^{\circ}$ Primaria \\
\hline
\end{tabular}



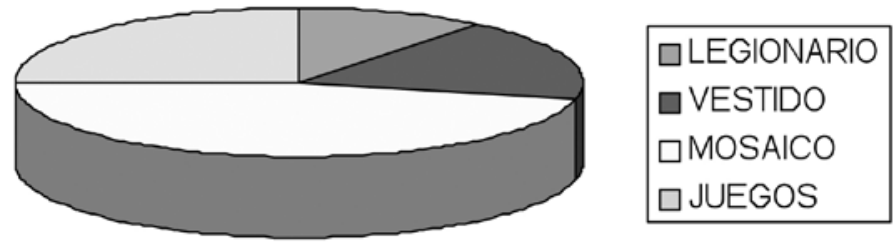

Figura 11. Talleres del museo de romanización. Calahorra

\section{Valoración}

Hemos contribuido a dar a conocer el patrimonio arqueológico de época romana no solo de Calahorra sino de la Rioja en general, acercando las colecciones y las piezas de arqueología romana al público infantil de una manera entretenida y lúdica.

Se ha conseguido la sensibilización hacia la conservación del patrimonio, que forma parte de la historia de un pueblo y en especial el patrimonio arqueológico como transmisor de la cultura romana a través de sus bienes materiales con valor histórico, artístico, etc. que nos han permitido el aprendizaje de otros modos de vida, de los elementos de su vida cotidiana o de sus gustos y manifestaciones artísticas.

Se ha logrado la aproximación de las piezas a los niños, así como el conocimiento de los materiales en que éstas han sido realizadas (mármol, piedra, madera, metal...), sus funciones, utilidades, etc., su contexto histórico, social y económico y su reflejo en piezas actuales.

¿Qué ha aportado cada uno de los talleres? El taller del legionario romano ha permitido al público infantil conocer las actividades bélicas y el uniforme del soldado romano, sus armas, su modo de vida, etc. El taller del mosaico romano ha contribuido a dar a conocer las técnicas, herramientas y métodos de elaboración de los pavimentos musivarios romanos. El taller del vestido ha puesto de relieve la moda, así como la indumentaria y complementos de la civilización romana. El taller de los juegos ha mostrado las actividades lúdicas, costumbres de ocio y tiempo libre de la antigua Roma.

Se ha despertado el interés de los niños en la visita al Museo acompañados por sus padres y la curiosidad por otros temas y piezas expuestas, pudiendo ampliar la información a través de las pantallas táctiles interactivas ubicadas en las Salas I y II de la planta baja o a través del audiovisual de la planta segunda.

Hemos desarrollado en ellos la capacidad de observación y análisis de las piezas expuestas en el Museo de la Romanización de la Rioja en Calahorra, que les han permitido un aprendizaje de la cultura y civilización de época romana.

Ha potenciado una serie de valores educativos a las distintas etapas de la Educación Infantil y Primaria como son los siguientes: conocimiento del medio natural, social y cultural, valorar el patrimonio natural, histórico y cultural de España y de La 
Rioja, respetando su diversidad y desarrollando la sensibilidad artística y el interés por colaborar activamente en su conservación y mejora. En lo que respecta al Bloque 5. Historia. El cambio en el tiempo, los contenidos de la actividad desarrollada se relacionan en el caso de Primer ciclo de Educación Primaria con los temas: La riqueza histórica del entorno próximo. Construcciones civiles y religiosas. Cuidado y conservación y Aproximación a la Historia: algunos acontecimientos relevantes del pasado. En lo que respecta a segundo ciclo de educación Primaria se han potenciado los contenidos relacionados con los temas que Ilevan por título: Las grandes civilizaciones y sus aportaciones al progreso de la Humanidad. Rasgos diferenciales de las sociedades a través del tiempo; Acontecimientos y personas relevantes en la historia de España y La riqueza artística de La Rioja. Reconocimiento y valoración del patrimonio artístico. Y por último, en lo que respecta a Tercer ciclo de Primaria: Aspectos básicos de la Historia de España y, de manera particular, de La Rioja: Prehistoria y Edad Antigua en La Rioja y en España. La Romanización.

La actividad ha permitido potenciar y transmitir una serie de valores educativos que tocan aspectos relacionados con la Educación Física, en concreto el Bloque 5, que lleva por título Juegos y deportes, y más específicamente las unidades: El juego como actividad común a todas las culturas. Realización de juegos libres y organizados en los que se utilicen las habilidades básicas y Conocimiento y disfrute de los juegos tradicionales de La Rioja como elemento para conocer nuestras costumbres e historia.

La iniciativa ha tenido una buena acogida por parte de los centros educativos ya que participaron en ella 28 grupos escolares, no solo de la propia Calahorra, sino de la Rioja Baja, muestra de ello es la participación en el mismo del CRA (Centro Rural Agrupado) de Ausejo. Hasta el punto que un mismo curso escolar se inscribía en los cuatro talleres, caso del Colegio San Andrés de Calahorra. Desde el punto de vista del aprendizaje, hemos obtenido unos resultados óptimos, ya que se trata de un público interesado y motivado. También los profesores se han implicado en estas actividades hasta el punto de colgar imágenes de los talleres en las respectivas páginas web de los colegios (Quintiliano, Teresianas y Ángel Oliván) o de publicar las actividades en la revista del respectivo colegio, como es el caso del Colegio San Andrés.

Los talleres más solicitados han sido el mosaico romano y los juegos, seguidos en menor medida por el vestido y el legionario romano. A partir de la instalación del audiovisual en la última planta, la actividad se completaba en los últimos diez minutos del taller con la proyección del mismo.

El grado de satisfacción de los usuarios, en este caso los niños en edades escolares comprendidas entre los siete y doce años, que han participado en alguno o varios de los talleres es altísimo, ya que les he permitido:

- Descubrir el mundo de la arqueología, en este caso de época romana, desconocida para la mayoría de ellos.

- Acercarse al museo y conocer sus contenidos, en este caso los elementos materiales que nos ha legado la cultura romana.

- Adquirir un conocimiento global de las características de la sociedad romana.

- Poder realizar la visita en un futuro acompañados de sus padres o familiares. 
- Aproximación de la civilización romana, desconocida para la mayoría de ellos, lo que les ha permitido obtener una visión distinta de la misma.

- Observar y percibir las transformaciones que ha sufrido el paisaje, debido a la acción antrópica.

La atención prestada por los distintos medios de comunicación de la ciudad ha servido también de incentivo para potenciar la actividad didáctica y difundirla.

\section{Locuciones latinas}

A continuación recogemos en el siguiente cuadro las distintas locuciones latinas que los grupos escolares han tenido la oportunidad de aprender en cada uno de loa talleres:

\begin{tabular}{|c|c|l|l|}
\hline TALLER & \multicolumn{1}{|c|}{ SALA } & \multicolumn{1}{c|}{ LOCUCIÓN } & \multicolumn{1}{c|}{ TRADUCCIÓN } \\
\hline Legionario romano & Sala II & VENI, VIDI, VICI & vine vi vencí \\
\hline Mosaico romano & Sala II & CAVE CANEM & cuidado con el perro \\
\hline Vestido romano & Sala III & $\begin{array}{l}\text { CEDANT ARMAS } \\
\text { TOGAE }\end{array}$ & que las armas cedan a la toga \\
\hline Juegos romanos & Sala V & $\begin{array}{l}\text { MORITURI TE } \\
\text { SALUTANT }\end{array}$ & los que van a morir te saludan \\
\hline Juegos romanos & Sala V & ALEA IACTA EST & la suerte está echada \\
\hline Juegos romanos & Sala V & CARPE DIEM & disfruta el momento \\
\hline Juegos romanos & Sala V & $\begin{array}{l}\text { MENS SANA IN } \\
\text { CORPORE SANO }\end{array}$ & mente sana en cuerpo sano \\
\hline
\end{tabular}

\section{REFERENCIAS BIBLIOGRÁFICAS}

ALDEROQUI, S. (1996). Museos y escuela: socios para educar. Barcelona: Paidos.

ASENSIO, M. y POL, E. (2002). Nuevos escenarios de educación. Aprendizaje informal sobre el patrimonio, los museos y la ciudad. Buenos Aires.

AVILA, R.; CRUZ, A. y DIEZ, Ma. C. (eds.) (2008). Didáctica de las Ciencias Sociales, Currículo Escolar y Formación del Profesorado. La didáctica de las Ciencias Sociales en los nuevos planes de estudio. Jaén.

BALLART, J. (1997). El patrimonio histórico y arqueológico: valor y uso. Barcelona: Ariel. BELDA, C. y MARTÍN, Ma. T. (eds.) (2002). Quince miradas sobre los museos. Murcia: Universidad de Murcia, Servicio de Publicaciones, Fundación Cajamurcia.

CALAF MASACHS, R. y FONTAL MERILLAS, O. (coords.) (2004). Comunicación educativa del patrimonio: referentes, modelos y ejemplos. Gijón: Trea. 
CAR (2007). Decreto 25/2007 de 4 de mayo por el que se establece el Curriculo de Segundo Ciclo de Educación Infantil en la Comunidad Autónoma de la Rioja, (BOR núm. 62 de 8 de mayo de 2007).

CAR (2011 a) Decreto 4/2011 de 28 de enero por el que se establece el Curriculo de la Educación Primaria en la Comunidad Autónoma de la Rioja (BOR núm. 16 de 4 de febrero de 2011).

DE LOS POLOS HERRADOR, M. y DE LOS GONZÁLEZ, M. (1994). Los departamentos de Educación y Acción Cultural en los museos. Iber: Didáctica de las ciencias sociales, geografía e historia (ejemplar dedicado a El patrimonio histórico artístico), 2, 7-28.

DOMINGUEZ, C. (1999). El Museo. Un espacio para el aprendizaje. Huelva: Servicio de Publicaciones de la Universidad de Huelva.

FONTAL MERILLAS, O. (2003). La Educación patrimonial: teoría y práctica para el aula, el museo e Internet. Gijón: Trea.

GARCÍA BLANCO, A. y SANZ MARQUINA, T. (1979). El departamento educativo en el museo. Boletín de la ANABAD, tomo 29, 4, 45-49.

GARCÍA BLANCO, A. (1988). Didáctica del museo. El descubrimiento de los objetos. Madrid: Ediciones de la Torre.

GARCÍA BLANCO, A.; PÉREZ SANTOS, A. y ANDONEGUI, M. (1999). Los visitantes del museo: un estudio de público. Madrid: Ministerio de Educación y Cultura.

GONZÁLEZ BLANCO, A.; JIMÉNEZ, J. L. y CINCA, J. L. (1995). Un nuevo testimonio de juegos circenses también del ceramista Gaius Valerius Verdullus. En Beltrán, F. (ed.) Roma y el nacimiento de las culturas epigráficas en Occidente. Zaragoza: Institución Fernando el Católico, 251-254.

HERRERA ESCUDERO, M. L. (1971). El museo en la educación. Su origen, evolución e importancia en la cultura moderna. Barcelona-Madrid: Index.

HOOPER GREEN-HILL, E. (1998). Los museos y sus visitantes. Gijón: Trea.

JIMÉNEZ MANERO, E. (1999). Un vaso con representación de gladiadores en Calahorra. Kalakorikos: revista para el estudio, defensa, protección, y divulgación del patrimonio histórico-artístico y cultural de Calahorra y su entorno, 4, 245-255.

LUEZAS PASCUAL, R. A. (2011). Museo municipal de Calahorra: 25 años. Belezos. Revista de cultura popular y de tradiciones de la Rioja, 15, 28-33.

LLANOS ORTIZ DE LANDALUCE, A. (2002.). Tableros de juego en el patrimonio arqueológico de Álava. Estudios de Arqueología Alavesa, 19, 191-196.

MAYER OLIVÉ, M. (1998). Propuesta de lectura para el vaso de los circenses del alfar de La Maja. Kalakorikós: revista para el estudio, defensa, protección, y divulgación del patrimonio histórico-artístico y cultural de Calahorra y su entorno, 3, 187-192.

M.E.C. (2006). La Ley Orgánica de Educación 2/2006 de 3 de mayo, BOE núm. 106 de 4 de mayo de 2006.

M.E.C. (2006). Real Decreto 1513/2006 por el que se establecen las enseñanzas mínimas de Educación Primaria, BOE núm. 293 de 8 de diciembre de 2006.

PASTOR HOMS, M. I. (2004). Pedagogía museística. Nuevas perspectivas y tendencias actuales. Barcelona: Ariel. 
SÁNCHEZ-TRUJILLANO, M. T. (2011). Museo de la Romanización. Belezos. Revista de cultura popular y de tradiciones de la Rioja, 15, 80-84.

SANTACANA MESTRE, J. y SERRAT ANTOLÍN, N. (coord.) (2007). Museografía Didáctica. Barcelona: Ariel.

VALDÉS SAGUÉS, M. C. (1999). La difusión cultural en el museo. Servicios destinados al gran público. Gijón: Trea.

ARNALDO, J. (dir.) (2009). Los museos en la educación: la formación de los educadores. I Congreso Internacional (2008. Madrid). Madrid: Museo Thyssen-Bornemisza. 